\title{
Laparoscopic left lobe liver resection in a porcine model: a study of the efficacy and safety of different surgical techniques
}

\author{
Kristinn Eiriksson - Diddi Fors - Sten Rubertsson • \\ Dag Arvidsson
}

Published online: 3 April 2009

(C) Springer Science+Business Media, LLC 2009

\section{Erratum to: Surg Endosc}

DOI 10.1007/s00464-008-0115-6

The correct order of the authors' names is:

Kristinn Eiriksson, Diddi Fors, Sten Rubertsson and Dag Arvidsson.

The online version of the original article can be found under doi:10.1007/s00464-008-0115-6.

K. Eiriksson $(\bowtie)$

Department of Surgery, Stavanger University Hospital, P.O. Box 8100, Stavanger, Norway

e-mail: kristinn.e@bigfoot.com

D. Fors · S. Rubertsson

Department of Surgical Sciences/Anesthesiology and Intensive

Care, Uppsala University, Uppsala, Sweden

D. Arvidsson

Department of Surgical Sciences, Uppsala University,

Uppsala, Sweden 